\title{
Childhood Imaginary Companion and Schizotypy in Adolescents and Adults
}

\author{
Tohid Zarei ${ }^{1}$, Abbas Pourshahbaz ${ }^{1}$, Marjan Poshtmashhadi ${ }^{1}$ \\ 1. Department of Clinical Psychology, University of Social Welfare and Rehabilitation Sciences, \\ Tehran, Iran
}

Corresponding Author: Abbas Pourshahbaz, Department of Clinical Psychology, University of Social Welfare and Rehabilitation Sciences (USWR), Koodakyar Ave., Daneshjoo Blvd., Evin District, Tehran, Iran. Telephone: +982122180083, Fax: +982122180109, Email: apourshahbaz@yahoo.com

In press, Journal of Anomalous Experience and Cognition 


\begin{abstract}
Background: Previous studies have reported associations between childhood imaginary companion (CIC) and creativity, inclination toward fantasy, and hallucination-like experiences. However, these relations have not been examined systematically within a personality construct. The aim of this study was to investigate the association of CIC status and schizotypy levels of adolescents and adults within the framework of the Hierarchical Taxonomy Of Psychopathology (HiTOP).
\end{abstract}

Design: Participants were 255 Iranian adolescents and adults (15 to 67 years old) responding mostly via e-questionnaires on a website (156 females). They were grouped based on their childhood IC status. Schizotypy dimensions (based on a fully dimensional conceptualization of schizotypy; Claridge's model) were compared between these two groups. Two subscales of the Achenbach System of Empirically-Based Assessment-Youth Self-Report (ASEBA-YSR) corresponding to thought disorder and detachment spectra of the HiTOP model were correlated with the unusual experiences (UnEx) and introvertive anhedonia (IntAn) dimensions of the short scale of Oxford-Liverpool Inventory of Feelings and Experiences (sO-LIFE) among adolescents. Additionally, subscales of the ASEBA-YSR were compared between CIC and non-IC groups among adolescents. In adults, correlations of 'Big Five' domains of the NEOFive Factor Inventory (NEO-FFI) with schizotypy dimensions were evaluated.

Results: The UnEx, and ImpNon dimensions and overall sO-LIFE scores of the CIC group were higher than the non-IC group. There was positive correlation between the UnEx dimension and the Thought Problems subscale among adolescents. Neuroticism domain of the NEO-FFI was strongly correlated with overall schizotypy and the cognitive disorganization (CogDis) dimension of sO-LIFE. Additionally, it was the only domain of the NEO-FFI in which adults in the CIC group scored higher than their peers.

Conclusions: Report of CIC in adolescents and adults is associated with a set of schizotypy dimensions in line with the concept of "happy schizotype".

Keywords: positive schizotypy, imaginary friend, psychosis superspectrum 


\section{Introduction}

Childhood imaginary companion (CIC) is a fantasy character created by some children throughout development. As the term suggests, ICs are vivid pretend characters (e.g., people, animals, fictional creatures) that the children having them act as if they are real and interact with them (e.g., talk to them, refer to them by name) in their daily activities as well as in their play (Taylor, 1999). Svendsen (1934, p. 988) defined an imaginary friend as: “an invisible character named and referred to in conversation with other persons or played with directly for a period of time, at least several months, having an air of reality for the child, but no apparent objective basis." Reports of ICs are as diverse and distinctive as children's personalities. As an example, Taylor (1999, p. 8) described ICs of a 4-year-old girl as "two invisible birds named Nutsy and Nutsy... lived in a tree outside her bedroom window... had brightly colored feathers... they [parents] regularly observed their daughter talking and playing with them..." Svendsen's definition of ICs has been employed in most of the scientific literature ever since. However, this definition fails to take into account another very similar phenomenon: personified objects (POs). They are stuffed animals and dolls that children treat as if they were real and had a personality of their own (Davis, 2020). For POs to count as ICs, they must align with Svendsen's definition; this excludes transitional objects as POs. A closely related fantasy play to ICs is impersonation (imaginary identities). Impersonation happens when children create imaginary characters and impersonate them on a regular basis (Taylor, 1999; Taylor et al., 2013). In addition to the phenomenological overlaps of the experiences, these two phenomena have been shown to have similarities with invisible ICs in regard to the higher level of theory of mind (ToM) of the children having them (Taylor \& Carlson, 1997). Nevertheless, there are also studies showing differences between invisible ICs and POs regarding the relationship children have with them (Gleason, 2002): relationship with the former being more like with peers (i.e., "horizontal"), while children interact with the latter in a more nurturing and care-giving style (i.e., "vertical"). This might be the reason why children with invisible ICs were found to receive more positive peer nominations than children having POs (Lin et al., 2018).

Scientific investigation of ICs has been through a turbulent history. Earlier studies associated them with an array of deficits in personality and disordered characteristics (Vostrovsky, 1895). For instance, Svendsen (1934) described children having ICs as timid in the presence of other children. But more recent studies did not find such differences between children with and without ICs (Mauro, 1991), or even reported adaptive role of ICs in the lives 
of children (Bender \& Vogel, 1941). One explanation for these opposing findings is the recruitment of samples from outpatient clinics and without control groups in earlier studies (Taylor, 1999). Indeed, prevalence rates of children having ICs, 13 to $65 \%$, emphasize the normality of this phenomenon (Davis et al., 2019; Pearson, 1998; Svendsen, 1934; Taylor et al., 2004). Moreover, research into personality characteristics and behavioral correlates of IC play demonstrated a range of positive attributes. This type of imaginative play was reported to provide children with a more advanced theory of mind (Giménez-Dasí et al., 2014; Taylor \& Carlson, 1997) and greater positive adjustment in high-risk pre-adolescents (Taylor et al., 2010).

Additionally, studies have found relations between having ICs and scoring higher on creativity scales (Hoff, 2005). Schaefer (1969) reported that adolescents with a history of IC play were more likely to belong to the creative group of their study compared with peers without it. This finding was shown among adults as well (Kidd et al., 2010). Another relevant line of research associated IC play with fantasy-oriented activities. In a longitudinal study, oneyear-old toddlers showing tendency toward fantasy-based toys were more likely to engage in IC play at the age of four than those preferring reality-based toys (Acredolo et al., 1995). Furthermore, adult fiction writers tend to report more memories of childhood ICs than population norms (Taylor et al., 2003).

Inclination toward fantasy and more advanced imaginative abilities among those with IC play experience was further explored in other studies (Firth et al., 2015) . Trionfi and Reese (2009) found that children with ICs are better able to tell detailed narratives about a story and also a personal experience than their peers. In a study of 102 female students, Gleason et al. (2003) found associations between having ICs and more imagery use, as well as more vivid night dreams and violent daydreams. Similarly, children with ICs were reported by parents to be highly imaginative, use myth in their games, and refer to events as magical (Bouldin \& Pratt, 1999). Relevantly, readiness for daydreaming was found to be the most reliable predictor for using a diary in the role of an imaginary friend among adolescent diarists (Seiffge-Krenke, 1997). Collectively, these studies found links between having ICs and showing higher fantasyproneness among different age groups.

Taking into account this proposed link, there have been studies on personality correlates of fantasy-proneness. In a recent meta-analysis of 132 articles comprising 24,007 participants, Merckelbach et al. (2021) demonstrated large effect sizes $(r s>.50)$ for hallucination-like 
experiences, magical ideation, aberrant perceptions, dissociation, and daydreaming, as correlates of fantasy-proneness. Earlier studies showed better hallucinatory ability of fantasizers compared to those low and medium in fantasy-proneness (Lynn \& Rhue, 1988).

Childhood IC status has been also proposed to be directly related to the propensity to hallucinate (Pearson et al., 2001). This was shown using ambiguous auditory stimuli tasks (e.g., Jumbled Speech task) in which IC children reported hearing more meaningful words than a control group (Fernyhough et al., 2007). Davis and colleagues (2019) demonstrated that adult reports of childhood IC predicted prodromal symptoms of hallucination with childhood adversity partially mediating this relation. Furthermore, using both an auditory signal detection task (needing participants to detect speech in embedded noise) and the Launay-Slade Hallucination Scale-revised (LSHS-revised; Bentall \& Slade, 1985), Fernyhough and colleagues (2019) found a bias towards detecting speech in white noise as well as higher auditory verbal hallucination (AVH) scores in adults with a history of childhood ICs. It is necessary to mention that hallucinating per se is not an indicator of pathology (Bentall, 2014), $10 \%$ of the general population experience hallucinations without necessarily being diagnosed with any mental disorder (Bentall \& Slade, 1985; Posey \& Losch, 1983; van Os et al., 2000).

Relatedly, schizotypy is a multidimensional personality construct that, according to Claridge (1997), results from a combination of genetic, environmental and personality factors and has a normal distribution in the general population. It represents the underlying predisposition in a quasi/fully dimensional view of schizophrenia that expresses itself across a broad range of personality, subclinical, and clinical phenomenology (Kwapil \& Chun, 2015).

The quasi-dimensional perspective of schizotypy originates in the clinical tradition that identified mild symptoms of schizophrenia in the relatives of patients (Bleuler, 1950; Kraepelin, 1919). Later, Meehl (1962) described schizotypy as a personality organization that is taxonic in nature and shows liability for schizophrenia (Lenzenweger, 1998). It was shown (Morrison et al., 2002) that individuals at high risk for later developing psychosis also scored higher in a schizotypy inventory (Oxford-Liverpool Inventory of Feelings and Experiences [OLIFE], Mason et al., 1995). There is also longitudinal evidence that those with an increased genetic risk of psychosis, also report higher levels of schizotypy than controls (Miller et al., 2002). However, a potential risk of psychosis does not mean actual conversion to full-blown disorder in the majority of the cases reporting higher levels of schizotypy, and it may have adaptive manifestations as well (Claridge, 1997; Claridge \& Beech, 1995). Claridge's model 
posited the dimensionality of schizotypy not only in the clinical and subclinical ranges (as in the quasi-dimensional view), but also as part of normal individual differences including healthy expressions such as creativity (Kwapil \& Barrantes-Vidal, 2015). Longitudinal studies have reported that the majority of those scoring high in self-reported schizotypy scales never end up having a psychiatric disorder (Chapman et al., 1994; Gooding et al., 2005).

Ascribing both adaptive and pathological sides to schizotypy is relevant to the heterogenous nature of this construct, which manifests itself in its multidimensionality (Mohr $\&$ Claridge, 2015). The three-factor construct of schizotypy, as the most widely accepted view, comprises positive, negative, and disorganization dimensions, and has been established in factor analysis studies (Bentall et al., 1989; Raine, 1991). In addition to these three factors, Claridge and colleagues (Mason et al., 1995; Mason et al., 2005) suggested a fourth dimension -impulsive nonconformity- based on overlapping conditions between psychosis and bipolar disorder, proposing these two to lie on a continuum.

The positive dimension of schizotypy includes traits like unusual experiences (aberrant perceptions and hallucination-like experiences), eccentric ideas (magical and not based in reality), and fantasy proneness (vivid imagination and immersion in inner experiences) (Claridge \& Beech, 1995; Fonseca-Pedrero et al., 2021; Kotov et al., 2020). Aforementioned links between schizotypy and creativity is mostly due to the positive dimension (and also impulsive nonconformity dimension) being at work (Batey \& Furnham, 2008; Mohr et al., 2001); especially because positive schizotypy enhances convergent (Gianotti et al., 2001) and more importantly, divergent (Jones et al., 2011) styles of thinking.

This dimension is also linked to different enriching experiences (Mohr \& Claridge, 2015). For example, in an experimental setting enhancing an altered state of consciousness (using shamanic-like techniques), high scorers on positive schizotypy experienced significant altered phenomenology, compared to low scorers (Rock et al., 2008). This experience along with other fairly uncommon experiences, believed to deviate from usual experience or from the consensually accepted view of reality, are collectively called anomalous experiences (AE) (Cardeña et al., 2014).

Importantly, association between subjective evaluation of AEs and schizotypy was shown to be moderated by cognitive disorganization dimension (Schofield \& Claridge, 2007); as cognitively disorganized participants showed a negative schizotypy/distressing experiences pattern, in contrast to organized ones who manifested a positive schizotypy/pleasant 
experiences relationship. This finding emphasizes the adaptive value of positive schizotypy, specifically in the absence of negative and disorganized dimensions (Goulding, 2004; Holt et al., 2008; Mohr \& Claridge, 2015; Tabak \& Weisman de Mamani, 2013).

The negative or deficit dimension of schizotypy -introvertive anhedonia- is the interpersonal aspect of this construct, mainly characterized by social and physical anhedonia, lack of energy, and introversion (Mason et al., 2005). This dimension is mostly responsible for the diminished quality of life, social functioning and wellbeing of those scoring high on schizotypy scales (Cohen \& Davis, 2009; Horan et al., 2007). The third factor in schizotypy is the cognitive disorganization dimension which describes poor attention and concentration, in addition to lowered decision-making abilities (Mason et al., 1995). It was shown to be associated with weak cognitive control and increased emotionality (Kerns, 2006). Impulsive nonconformity dimension is associated with antisocial behavior and affective episodes (Chapman et al., 1984). It was found to be related to Eysenck's Psychoticism Scale and its moderate scores was shown to be related to the preference for a non-conforming way of life (Mason et al., 1995).

Phenomenological aspects of childhood ICs (Pearson, 1998), its association with creativity (Hoff, 2005; Kidd et al., 2010; Schaefer, 1969) and fantasy-proneness (Bouldin \& Pratt, 1999; Firth et al., 2015; Gleason et al., 2003; Seiffge-Krenke, 1997; Trionfi \& Reese, 2009), and its direct relation with hallucination-like experiences (Davis et al., 2019; Fernyhough et al., 2019; Pearson et al., 2001) seem to have overlaps with traits and correlates of positive schizotypy and as such, having ICs can be considered as an early phenotype of tendency towards (positive) schizotypy later in adolescence and adulthood.

To put these two variables in the right dimensional framework, two different personality and behavioral scales (i.e., one for adolescents and another for adults), in accordance with Hierarchical Taxonomy of Psychopathology (HiTOP), were administered. These two scales were used to explore possible personality traits and pathological tendencies in the groups of this study. The benefit for the inclusion of the Achenbach System of Empirically-Based Assessment-Youth Self-Report (ASEBA-YSR) and the NEO Five-Factor Inventory (NEOFFI) for adolescents and adults, respectively, was twofold. First, to address what FonsecaPedrero et al. (2021) mentioned as a challenge of future studies on schizotypy to integrate this construct's traits into personality and psychopathology classifications. Second, probing into personality traits and pathological tendencies of having CIC seemed imperative. 
The HiTOP model has emerged as a research-driven endeavor to address limitations of traditional taxonomies of psychopathology (Kotov et al., 2017). This system views mental maladaptive characteristics and phenomena dimensionally (i.e., psychological function ranging from normal to abnormal) and to this end, uses dimensional measures to assess its components, syndromes, and spectra. Psychosis, as one of its three main superspectra (along with emotional dysfunction and externalizing superspectra), includes two narrower spectra: thought disorder and detachment. The thought disorder spectrum captures individual differences ranging from ordinary and uncreative thinking to perceptive and cognitive style insubstantially based in reality. It comprises symptoms and traits of positive schizotypy. The detachment spectrum mostly represents affective expressions and sociability individual differences including introversion and negative schizotypy (Kotov et al., 2020).

The HiTOP model as an evolving system needs time to build a comprehensive assessment instrument and for this reason measures compatible with this model are introduced to be used by researchers (Conway et al., 2019). The Achenbach System of Empirically-Based Assessment-Youth Self-Report (ASEBA-YSR) is one of such measures to be used in child and adolescent population (Achenbach \& Rescorla, 2001). Two subscales of ASEBA-YSR were found to comprise aspects of thought disorder (i.e., Thought Problems subscale) and detachment (i.e., Withdrawn/Depressed subscale) spectra of the HiTOP model (Kotov et al., 2020).

Among adolescents in this study, Thought Problems and Withdrawn/Depressed subscales were hypothesized to be related to the positive and negative schizotypy scales, respectively, as it was found that these two dimensions of schizotypy map onto the two spectra of psychosis superspectrum (Cicero et al., 2014; Moorman \& Samuel, 2018). The relationship of having childhood IC with different behavioral subscales of ASEBA-YSR was also explored by comparison with the NIC group to unpack possible pathological tendencies in this group of adolescents. The ASEBA-YSR measures behavioral syndromes in child and adolescent population. Thus, a personality inventory (i.e., NEO-FFI), based on an established model of personality was used for the adult sample of this study.

The five-factor model (FFM) of personality (Widiger \& Costa Jr, 2013) is based on one of the most widely accepted theories of personality within psychology (Rosellini \& Brown, 2011). NEO Five-Factor Inventory (NEO-FFI) was developed (Costa \& McCrae, 1992) as a briefer measure to assess the "Big Five" of the FFM: 1) neuroticism (N) is the degree of 
responding with emotional and psychological distress to stressors; 2) extraversion (E) measures sociability and experiencing positive emotionality in response to social situations; 3 ) openness to experience $(\mathrm{O})$ relates to the level of curiosity and being adventurous in response to new experiences; 4) agreeableness (A) pertains to the degree of cooperativeness and altruism; and 5) conscientiousness (C) is relevant to the level of self-control and planning abilities. This dimensional measure of personality is in harmony with the HiTOP model (Conway et al., 2019) and was administered in the adult sample of this study to explore personality traits associated with schizotypy and childhood IC.

Among five factors of the FFM, positive relation of neuroticism with total schizotypy (Asai et al., 2011; Gurrera et al., 2005), and positive schizotypy (Asai et al., 2011; Shi et al., 2018) was reported. Extraversion was shown to be negatively related to negative schizotypy (Rawlings \& Freeman, 1997). Additionally, openness to experience is assumed to be positively associated with positive schizotypy (Edmundson et al., 2011; Ross et al., 2002).

To date, no studies have directly investigated the relation between having childhood ICs and scoring higher on schizotypy inventories among adolescents and adults. This study mainly aimed to find differences between the two groups of adolescents and adults (the CIC and NIC groups) in scores of schizotypy dimensions. As the reports of positive schizotypy reduce with age after adolescence (Fonseca-Pedrero et al., 2018) and also due to overall decrease in schizotypal traits with increasing age (Fonseca-Pedrero et al., 2012), both adolescents and adults were included in this study to examine if any different patterns would be observed.

\section{Hypotheses}

1) Adolescents and adults with a history of IC play will score higher on Unusual Experiences dimension and total score of sO-LIFE schizotypy scale than the ones without such history.

2) Scores on Thought Problems and Withdrawn/Depressed subscales of the ASEBA-YSR will be positively correlated with scores on Unusual Experiences and Introvertive Anhedonia dimensions of sO-LIFE, respectively, among adolescents.

\section{Exploratory Questions}

1) What patterns of correlations will be observed between four dimensions of the SO-LIFE schizotypy scale and five factors of the NEO-FFI among adults? 
2) How will adolescents with IC play history score differently from their peers regarding their scores on ASEBA-YSR subscales?

3) What differences will emerge between adults with childhood IC experience and those without such experience in regard to NEO-FFI domains?

\section{Methods}

\section{Design}

This study was a survey-based, retrospective comparative research between two groups of participants with (CIC) and without IC play history NIC). Scores of sO-LIFE schizotypy dimensions, as well as ASEBA-YSR subscales and NEO-FFI domains were compared between the two groups, using independent groups t-tests. The moderating role of gender and age category was determined by ANOVAs. Correlations were also reported to determine relationships between sO-LIFE schizotypy dimensions and both ASEBA-YSR subscales and NEO-FFI domains. Data were analysed by IBM SPSS STATISTICS, version 26.

\section{Participants}

This study was approved by Iran's University of Social Welfare and Rehabilitation Sciences (USWR) research ethics committee. Adolescent data were gathered by two means: equestionnaires uploaded on a Persian website dedicated to this study (www.theimaginal.net), and same pen-and-paper questionnaires filled by high-school students after explaining the aims of the study. Data of adult sample were gathered solely by e-questionnaires on the aforementioned website. Online survey was advertised on social media outlets as a study on imaginary companions.

Target adolescent population were Iranian adolescents between 15 and 18 years of age. Sampling method was voluntary response sampling for online participants and convenience sampling for pen-and-paper method volunteers. Participants were 96 adolescents (61 females, $63.5 \%)$ aged $15-18$ years old $(M=16.88, S D=0.98)$. Sample consisted of 56 (49 females) online participants and 40 (12 females) pen-and-paper participants. Reliability of using equestionnaires for gathering of psychopathology data has been shown by Jones and colleagues (Jones et al., 2008). Sociodemographic data included age, gender, family order, and existence of current mental disorders. All participants completed this section. 
Adult participants of the study $(N=159 ; 95$ females, 59.7\%) were between 19 and 67 years of age $(M=25.18, S D=6.83)$. Sociodemographic data of adults were the same as adolescents and all participants completed this section. On the whole, 255 adolescents and adults (156 females, 61.2\%) participated in this study $(M=22.05, S D=6.75$, median $=21$ years).

\section{Measures}

The Imaginary Companion Questionnaire. As for the lack of a stantardized measure to assess childhood IC status and characteristics in adolescents and adults and also because we aimed to identify impersonation in addition to the two types of ICs (i.e., invisible and POs), a Persian researcher-made questionnaire was used for this purpose (Appendix 1).

At the beginning of the questionnaire, there was a description section to outline what IC and its types are. This description was written according to previous studies in the area (Svendsen, 1934; Taylor et al., 2004). In this study the occurrence of impersonation was also inquired; in accordance with earlier descriptions (Ames \& Learned, 1946; Taylor, 1999). To avoid mistaking impersonation for childhood role-play, due explanation was added after describing it.

There were also qualitative questions querying about the characteristics of ICs (e.g., gender, appearance, personality traits). These questions were used to validate the status of IC. Same measure was used for both adolescents and adults.

The Short Scale of Oxford-Liverpool Inventory of Feelings and Experiences, sO-LIFE (Mason et al., 2005). To assess schizotypy dimensions, Persian translation of Oxford-Liverpool Inventory of Feelings and Experiences-Brief scale (sO-LIFE) was used (Mason et al., 2005). This self-report scale includes 43 yes/no items covering four dimensions of schizotypy: Unusual Experiences (UnEx, 12 items), Cognitive Disorganization (CogDis, 11 items), Introvertive Anhedonia (IntAn, 10 items), and Impulsive Nonconformity (ImpNon, 10 items). The UnEx dimension describes perceptual anomalies, magical thinking, and hallucinations. It measures 'positive schizotypy'. The CogDis subscale tap poor attention and concentration in addition to weak decision-making and social anxiety. Lack of enjoyment from sources of pleasure is captured by IntAn dimension which reflects 'negative schizotypy'. Lastly the ImpNon scale describes impulsive and anti-social behavior pertaining to a lack of self-control. 
Due to the lack of a standardized translation of this measure in Persian, internal consistency was assessed by extracting Cronbach's alpha for the overall and each dimension of researcher's translation of sO-LIFE. The results are reported in Table 1. Same measure was used for both adolescents and adults.

Table 1. Cronbach's alpha of the Persian translation of SO-LIFE four dimensions and overall items.

\begin{tabular}{ccc}
\hline Scale & N. of items & Coefficient Alpha \\
\hline Overall Score & $41^{*}$ & 0.81 \\
\hline Unusual Experiences & 12 & 0.72 \\
\hline Cognitive Disorganization & 11 & 0.76 \\
\hline Introvertive Anhedonia & $8^{*}$ & 0.53 \\
\hline Impulsive Nonconformity & 10 & 0.59
\end{tabular}

*Note Two Items of IntAn dimension were deleted after reliability analysis

The Achenbach System of Empirically-Based Assessment-Youth Self-Report, ASEBA-YSR (Achenbach \& Rescorla, 2001). It is a questionnaire in line with the HiTOP model (Conway et al., 2019). This measure is appropriate for the school-aged children and adolescents (11 to 18 years of age). Syndromes section of this instrument contains 112 items needing participants to choose from three options $(0,1$, and 2$)$, specifying to what extent each item is true about them.

The ASEBA-YSR assesses nine subscales of behavioral problems and characteristics: Withdrawn/Depressed (8 items), Anxious/Depressed (13 items), Somatic Complaints (10 items), Social Problems (11 items), Thought Problems (12 items), Attention Problems (9 items), Rule-Breaking Behavior (15 items), Aggressive Behavior (17 items) and Other Problems (10 items, does not yield a sum score). Two higher order scales are also produced in the ASEBA-YSR: Internalizing score (31 items) is estimated by the sum of Withdrawn/Depressed, Anxious/Depressed, and Somatic Complaints subscales; Externalizing score (32 items) is estimated by the sum of Rule-Breaking and Aggressive Behaviors subscales. The ASEBA-YSR was used only for the adolescent sample of this study.

The NEO-Five Factor Inventory, NEO-FFI (Costa \& McCrae, 1992). It was administered to assess personality traits of the adult sample. This measure consists of 60 items, each describing 
a statement rated on a Likert scale $(1=$ strongly disagree to $5=$ strongly agree $)$. Each domain score of "Big Five" is derived by 12 items: neuroticism $(\mathrm{N})$; extraversion $(\mathrm{E})$; openness to experience $(\mathrm{O})$; agreeableness $(\mathrm{A})$; and conscientiousness $(\mathrm{C})$.

\section{Procedure}

A video clip was produced and uploaded on social media outlets (e.g., Instagram) to advertise the website dedicated to this study. Volunteers were to agree to an informed consent form prior to starting to fill in e-questionnaires. Answers to all of the questions were required (except for the descriptive ones) and participants could not move onto the next questionnaire before completing the previous one. Data were recorded only after all of the e-questionnaires were completed.

Pen-and-paper participants were approached by TZ in person. They were informed about the aim of the study and asked if they wanted to participate in it. Questionnaires were the same for both online and pen-and-paper participants. However, the ASEBA-YSR was administered only for the adolescents and the NEO-FFI was used only for adults.

\section{Results}

Of the 255 participants, $34.5 \%$ reported IC play $(N=88)$ while growing up. Additionally, $22.7 \%$ reported impersonation $(N=58)$. Females $(N=65)$ reported significantly more IC play than males $\left(\chi^{2}(N=255)=9.11, p<0.01\right)$. There was no significant difference of reporting CIC between adolescents and adults $(p>0.05)$. Table 2 demonstrates frequency, and percentage of participants based on their IC status and types. Descriptive statistics and comparison of scores between two groups of participants with (CIC) and without childhood IC (NIC) for age, gender, and sO-LIFE dimensions and overall schizotypy scores are reported in Table 3. 
Table 2. Frequency and percentage of IC status/types among all participants.

\begin{tabular}{|c|c|c|c|}
\hline IC status/type & Gender & Frequency & Percentage \\
\hline \multirow[t]{3}{*}{ Without IC } & Female & 91 & 35.6 \\
\hline & Male & 76 & 29.9 \\
\hline & Total & 167 & 65.5 \\
\hline \multirow[t]{3}{*}{ Invisible IC } & Female & 48 & 18.8 \\
\hline & Male & 17 & 6.7 \\
\hline & Total & 65 & 25.5 \\
\hline \multirow[t]{3}{*}{ Personified Object IC } & Female & 17 & 6.7 \\
\hline & Male & 6 & 2.3 \\
\hline & Total & 23 & 9 \\
\hline \multirow[t]{3}{*}{ Total } & Female & 156 & 61.1 \\
\hline & Male & 99 & 38.9 \\
\hline & Total & 255 & 100 \\
\hline
\end{tabular}

The sO-LIFE was completed by all participants (Table 3), with overall mean score of 18.71 and standard deviation of 6.58 . Females $(M=20.03, S D=6.14)$ reported significantly higher scores than males $(M=16.65, S D=6.75)$ on this scale $(t=4.12, p<0.001)$. On the UnEx dimension, same difference was seen $(t=3.7, p<0.001)$. But the gender difference was not significant on the other three dimensions at 0.001 level of significance. The normality of schizotypy dimensions and overall score was checked by observing their normal Q-Q plot and skewness. The highest value of skewness was seen in IntAn dimension (skewness $=0.71)$. 
Table 3. Descriptive statistics for age, gender, and SO-LIFE schizotypy dimensions according to childhood imaginary companion status: means followed by standard deviations.

\begin{tabular}{cccccccc}
\hline Variables & & $\mathbf{N}$ & $\mathbf{C I C}$ & $\mathbf{N}$ & $\mathbf{N I C}$ & $\mathbf{N}$ & Total \\
\hline Age & & 88 & 20.42 & 167 & 22.91 & 255 & 22.05 \\
& & & $(3.67)$ & & $(7.78)$ & & $(6.75)$ \\
\hline \multirow{2}{*}{ Gender } & Female & 65 & $25.5 \%$ & 91 & $35.7 \%$ & 156 & $61.2 \%$ \\
& Male & 23 & $9 \%$ & 76 & $29.8 \%$ & 99 & $38.8 \%$ \\
\hline \multirow{2}{*}{ sO-LIFE } & UnEx & 88 & 7.10 & 167 & 5.65 & 255 & 6.15 \\
& & & $(2.48)$ & & $(2.75)$ & & $(2.74)$ \\
\cline { 2 - 8 } & CogDis & 88 & 6.99 & 167 & 5.97 & 255 & 6.32 \\
& & & $(2.54)$ & & $(2.97)$ & & $(2.86)$ \\
\cline { 2 - 7 } & IntAn & 88 & 2.45 & 167 & 2.03 & 255 & 2.18 \\
& & & $(1.73)$ & & $(1.65)$ & & $(1.69)$ \\
\cline { 2 - 7 } & ImpNon & 88 & 4.91 & 167 & 3.62 & 255 & 4.06 \\
& & $(1.98)$ & & $(2.07)$ & & $(2.13)$ \\
\cline { 2 - 7 } & Overall & 88 & 21.45 & 167 & 17.27 & 255 & 18.71 \\
& & $(5.76)$ & & $(6.55)$ & & $(6.58)$
\end{tabular}

The relation between having childhood IC and scoring higher on sO-LIFE dimensions among all participants was investigated by comparing means of schizotypy scores between these two groups. Table 3 demonstrates this comparison by reporting means and standard deviations for overall schizotypy and its dimensions. To determine the significance of these differences, independent groups t-tests were analyzed.

The group of participants with a history of childhood IC scored significantly higher than the group without such history in overall schizotypy $(t=5.05, p<0.001)$, as well as in the $\operatorname{UnEx}(t=4.14, p<0.001), \operatorname{CogDis}(t=2.73, p<0.01)$, and $\operatorname{ImpNon}(t=4.81, p<0.001)$ dimensions. This difference was not seen in the IntAn dimension $(p>0.05)$.

Two exploratory ANOVAs with post-hoc Tukey tests were analysed to determine mean differences of overall sO-LIFE and the UnEx dimension between three groups: the CIC group, the NIC group without impersonation, and the NIC group with impersonation. No correction for multiple comparisons was applied. The Tukey tests revealed that for overall sO-LIFE and the UnEx dimension, means of the CIC group did not differ from the NIC group with 
impersonation $(p>0.05)$, while means of both groups were significantly higher than the NIC group without impersonation $(p<0.001)$.

The ASEBA-YSR was completed by adolescent participants, with Thought Problems subscale mean score of 6.96 and standard deviation of 4.57. Withdrawn/Depressed subscale mean score and standard deviation were 5.25 and 3.1, respectively. Females mean score of Thought Problems was significantly higher than males $(t=3.24, p<0.01)$. This difference was not seen in Withdrawn/Depressed subscale $(p>0.05)$.

Among adolescents in this study, relations between Thought Problems and Withdrawn/Depressed subscales of the ASEBA-YSR corresponding to thought disorder and detachment spectra of the HiTOP model, and the UnEx and IntAn dimensions of sO-LIFE, respectively, were estimated by Pearson correlation coefficients. Correlation between Thought Problems subscale and the UnEx dimension among all participants was relatively strong $(r=$ $0.59, p<0.001)$. Additionally, Withdrawn/Depressed subscale and the IntAn dimension were moderately correlated $(r=0.31, p<0.01)$. These correlations were partly seen in the two groups of adolescents, namely correlation between Thought Problems subscale and the UnEx dimension was 0.57 in the CIC group and 0.52 in the NIC group $(p<0.001)$. Weak significant correlation of 0.28 was found between the IntAn dimension and Withdrawn/Depressed subscale in the NIC group $(p<0.05)$, while they were not correlated in the CIC group of adolescents $(p>0.05)$.

To determine the degree of mean differences between two groups of adolescents (i.e., CIC and NIC) in their scores of Thought Problems and Withdrawn/Depressed subscales, independent groups t-tests were analysed. The group of adolescents with childhood IC scored significantly higher $(M=9.33, S D=4.41)$ than the group without childhood IC $(M=5.53, S D$ $=4.07)$ in scores of Thought Problems subscale $(t=4.29, p<0.001)$. The difference was also seen in Withdrawn/Depressed subscale $(t=2.51, p<0.05)$. To further explore differences between these two groups regarding their scores on ASEBA-YSR subscales, Table 4 reports on their comparison of means and results of independent t-tests analyses.

With the exception of Rule-Breaking Behavior subscale, there were significant mean differences in all the other subscales $(p<0.05)$ between the two groups with (CIC) and without childhood imaginary companion (NIC) (Table 4). Post-hoc ANOVAs, considering both gender and IC status effects on these subscales, revealed that with the exception of Somatic Complaints 
subscale, the main effects of IC status were found significant on these subscales $(p<0.05)$, and not the interaction effect of both $(p>0.05)$.

Table 4. Comparison of means and independent groups t-test results of ASEBA-YSR subscales among adolescents according to childhood imaginary companion status.

\begin{tabular}{ccccccc}
\hline & \multicolumn{2}{c}{ CIC $(\mathbf{N}=\mathbf{3 6})$} & \multicolumn{2}{c}{ NIC (N=60) } & \multicolumn{2}{c}{ t-test Results } \\
\cline { 2 - 6 } Internalizing & Mean & SD & Mean & SD & t value & p value \\
\hline Externalizing & 20.47 & 9.57 & 13.95 & 10.40 & 3.06 & $0.003^{* *}$ \\
\hline Anxious/Depressed & 9.78 & 4.98 & 6.50 & 5.01 & 3.11 & $0.002^{* *}$ \\
\hline Withdrawn/Depressed & 6.25 & 2.98 & 4.65 & 3.04 & 2.51 & $0.014^{*}$ \\
\hline Somatic Complaints & 4.44 & 3.69 & 2.80 & 3.60 & 2.15 & $0.034^{*}$ \\
\hline Social Problems & 5.92 & 3.17 & 4.12 & 2.62 & 3.01 & $0.003^{* *}$ \\
\hline Thought Problems & 9.33 & 4.41 & 5.53 & 4.07 & 4.29 & $0.001^{* *}$ \\
\hline Attention Problems & 8.17 & 3.46 & 6.28 & 3.40 & 2.76 & $0.007^{* *}$ \\
\hline Rule-Breaking Behavior & 6.58 & 4.30 & 5.12 & 3.36 & 1.86 & NS \\
\hline Aggressive Behavior & 10.11 & 5.24 & 7.85 & 4.51 & 2.24 & $0.028^{*}$ \\
\hline $\begin{array}{c}\text { Obsessive-Compulsive } \\
\text { Problems }\end{array}$ & 8.42 & 3.22 & 5.72 & 3.39 & 3.85 & $0.001^{* *}$ \\
\hline \begin{tabular}{c} 
PTSD Problems \\
\hline
\end{tabular} & 11.58 & 4.12 & 8.08 & 4.82 & 3.63 & $0.001^{* *}$ \\
\hline
\end{tabular}

Pearson correlation coefficients between five domains of NEO-FFI and schizotypy dimensions were estimated in all adult participants and according to their IC status. Table 5 demonstrates correlation matrix of these measures. 
Table 5. Correlation matrix between NEO-FFI domains and sO-LIFE schizotypy dimensions among all adults and also according to childhood imaginary companion status (CIC group $\mathrm{N}=52$, NIC group $\mathrm{N}=107$, and All adults $\mathrm{N}=159$ ).

\begin{tabular}{|c|c|c|c|c|c|c|c|c|c|c|c|c|c|c|c|}
\hline & \multicolumn{3}{|c|}{$\begin{array}{c}\text { Overall } \\
\text { Schizotypy }\end{array}$} & \multicolumn{3}{|c|}{ UnEx } & \multicolumn{3}{|c|}{ CogDis } & \multicolumn{3}{|c|}{ IntAn } & \multicolumn{3}{|c|}{ ImpNon } \\
\hline & $\mathrm{CIC}$ & NIC & All & $\mathrm{CIC}$ & NIC & All & $\mathrm{CIC}$ & NIC & All & $\mathrm{CIC}$ & NIC & All & $\mathrm{CIC}$ & NIC & All \\
\hline Neuroticism & $\stackrel{*}{*}$ & $\stackrel{\stackrel{*}{*}}{\stackrel{*}{0}}$ & $\frac{*}{*}$ & 艺 & $\stackrel{*}{\stackrel{*}{*}}$ & $\frac{*}{*}$ & $\frac{*}{*}$ & $\begin{array}{l}\frac{*}{*} \\
\stackrel{*}{0} \\
0\end{array}$ & \begin{tabular}{l}
$*$ \\
\multirow{*}{*}{} \\
$\stackrel{0}{0}$ \\
0
\end{tabular} & $\frac{\tilde{n}}{Z}$ & 浐 & 菊 & 蒡 & \begin{tabular}{l}
$*$ \\
\multirow{*}{*}{+} \\
\multirow{0}{+}{}
\end{tabular} & $\begin{array}{l}\stackrel{*}{*} \\
\stackrel{\infty}{+} \\
0\end{array}$ \\
\hline Extraversion & $\tilde{Z}$ & 草 & $\begin{array}{l}\stackrel{*}{*} \\
\stackrel{*}{*} \\
\stackrel{0}{\varphi}\end{array}$ & 艺 & 艺 & Zू & 艺 & $\begin{array}{l}* \\
* \\
\stackrel{*}{*} \\
\stackrel{+}{+} \\
\dot{1}\end{array}$ & \begin{tabular}{l}
$*$ \\
\multirow{*}{*}{} \\
$\stackrel{+}{+}$ \\
$\dot{0}$
\end{tabular} & 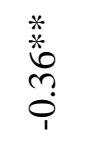 & \begin{tabular}{l}
$*$ \\
$*$ \\
\multirow{*}{*}{} \\
$\stackrel{n}{0}$ \\
$\varphi$
\end{tabular} & $\begin{array}{l}\frac{*}{*} \\
\stackrel{*}{n} \\
\stackrel{1}{1}\end{array}$ & $\stackrel{\tilde{0}}{\tilde{z}}$ & $\frac{*}{N}$ & $\begin{array}{l}\stackrel{*}{6} \\
\stackrel{0}{0}\end{array}$ \\
\hline $\begin{array}{l}\text { Openness to } \\
\text { Experience }\end{array}$ & $\tilde{\tilde{Z}}$ & $\stackrel{*}{m}$ & 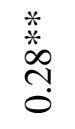 & $\stackrel{\tilde{a}}{\tilde{Z}}$ & $\stackrel{*}{\dddot{*}}$ & $\stackrel{*}{\circ}$ & $\frac{*}{n}$ & 艺 & $\begin{array}{l}* \\
\stackrel{*}{6} \\
0\end{array}$ & 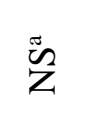 & $\tilde{\tilde{Z}}$ & $\tilde{Z}$ & 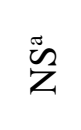 & $\begin{array}{l}\stackrel{*}{*} \\
\stackrel{*}{n} \\
0\end{array}$ & 芼 \\
\hline Agreeableness & $\tilde{\tilde{z}}$ & 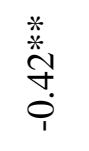 & $\begin{array}{l}* \\
\stackrel{*}{*} \\
\stackrel{+}{+} \\
\stackrel{9}{9}\end{array}$ & $\frac{\pi}{Z}$ & 䓀 & Zू & $\tilde{Z}$ & ثै & $\begin{array}{l}* \\
\stackrel{*}{0} \\
0 \\
\end{array}$ & 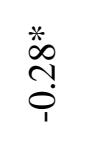 & $\begin{array}{l}\stackrel{*}{*} \\
\stackrel{*}{+} \\
\dot{+}\end{array}$ & $\begin{array}{l}\stackrel{*}{*} \\
\stackrel{*}{+} \\
\stackrel{0}{9}\end{array}$ & $\stackrel{*}{m}$ & 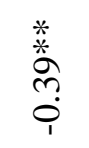 & 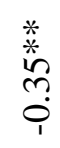 \\
\hline $\begin{array}{l}\text { Conscientious } \\
\text {-ness }\end{array}$ & $\begin{array}{l}* \\
\tilde{n} \\
n \\
0\end{array}$ & $\begin{array}{l}\stackrel{*}{*} \\
\stackrel{+}{+} \\
\dot{\varphi}\end{array}$ & $\begin{array}{l}* \\
* \\
\infty \\
m \\
? \\
\varphi\end{array}$ & $\stackrel{\tilde{0}}{Z}$ & 艺 & $\tilde{\tilde{Z}}$ & 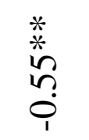 & $\begin{array}{l}\stackrel{*}{*} \\
\stackrel{*}{+} \\
\stackrel{9}{\varphi}\end{array}$ & \begin{tabular}{l}
$*$ \\
\multirow{*}{*}{} \\
\multirow{6}{+}{} \\
$\dot{0}$
\end{tabular} & 气̃ & $\stackrel{\stackrel{*}{ \pm}}{\stackrel{N}{\varphi}}$ & 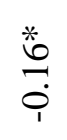 & $\stackrel{*}{\stackrel{*}{\sim}}$ & $\begin{array}{l}\stackrel{*}{*} \\
\stackrel{3}{m} \\
0\end{array}$ & 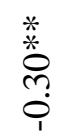 \\
\hline
\end{tabular}

As is demonstrated in Table 5, neuroticism domain of NEO-FFI was positively correlated with all dimensions of schizotypy ( $p<0.01$, moderate to strong associations), except for the UnEx and IntAn dimensions in the CIC group. Specifically, it was strongly correlated with overall schizotypy ( $r=0.57,0.7$, and 0.71$)$ and CogDis dimension $(r=0.61,0.67$, and 0.66$)$ in all three groups.

Extraversion, on the other hand, showed a negative trend of correlations with schizotypy dimensions, except for the UnEx dimension. Notably, it was strongly correlated with IntAn dimension in the NIC group and all adults $(r=-0.56$, and -0.51$)$, and interestengly with overall schizotypy $(r=-0.5)$ and CogDis dimension $(r=-0.45)$ only in the NIC group.

There were no strong correlations between openness to experience and schizotypy dimensions. The only moderate correlations were with ImpNon dimension in NIC group and 
all adults $(r=0.37$, and 0.34). Agreeableness showed moderate and negetive correlations with overall schizotypy ( $r=-0.42$, and -0.34$)$, and IntAn $(r=-0.49$, and -0.42$)$ in the NIC group and all adults, and with ImpNon $(r=-0.33,-0.39$, and -0.35$)$ in all three groups. Same negative pattern of correlations was seen for conscientiousness, as it was moderately correlated with overall schizotypy ( $r=-0.35,-0.41$, and -0.38$)$, CogDis $(r=-0.42$, and -0.46$)$, and ImpNon $(r$ $=-0.32,-0.3$, and -0.3$)$. It had negative and strong correlations with CogDis only in the CIC group $(r=-0.55)$.

Neuroticism was the only domain of NEO-FFI showing significant mean difference $(t$ $=2.42, p<0.05)$ between the two groups of adults with $(M=30.63, S D=6.7)$ and without childhood IC $(M=27.14, S D=9.15)$. As the assumption of homogeneity of variances was violated, the Mann-Whitney $U$ test was also analysed and the mean difference was found significant $(p<0.05)$.

An exploratory univariate two-way ANOVA was analysed to determine the interaction effect of gender and IC status on overall sO-LIFE score, as well as the UnEx, CogDis, and ImpNon dimensions among all participants. This is especially important to test whether the difference seen between the two groups of participants in these scales, was or was not moderated by gender. Homogeneity of subpopulations were checked by Levene's test and its results were found to be insignificant $(p>0.05)$.

Interaction effect of gender and IC status on overall schizotypy score was significant $(F=4.8, p=0.029)$. Similarly, main effect of both gender $(F=4.64, p=0.032)$ and IC status $(F=24.54, p<0.001)$ were found to be significant. Earlier in Results section it was reported that females scored higher than males on overall schizotypy score. On the UnEx dimension, interaction effect of gender and IC status was not significant $(p>0.05)$. This was in contrast to the significance of main effects of IC status $(F=15.87, p<0.001)$ and gender $(F=4.09, p=$ 0.044) on this dimension. Only the main effect of IC status was significant on the CogDis dimension $(F=6.74, p=0.01)$. Likewise, the ImpNon dimension was influenced solely by the IC status main effect $(F=23.18, p<0.001)$, and not gender main effect or the interaction of these two $(p>0.05)$. Consequently, gender moderated the effect of IC status on overall sOLIFE schizotypy scores, but not the UnEx, CogDis and ImpNon dimensions.

Another post-hoc univariate two-way ANOVA was interpreted to determine the interaction effect of age category and IC status on overall sO-LIFE and the UnEx, CogDis, and ImpNon dimensions. Age was categorized as "under 18", and "over 18". Test of homogeneity 
of subpopulations by Levene's test produced the same results for this analysis as well ( $p>$ 0.05). The interaction effect of age category and IC status on overall schizotypy was not significant $(p>0.05)$, while main effects of age category $(F=5.27, \mathrm{p}<0.05)$, and IC status $(F$ $=30.75, p<0.001)$ were significant. Same was true for the interaction effect of these two variables on the UnEx dimension $(p>0.05)$. In contrast, main effects of age category and IC status were significant on this dimension $(F=13.09$, and 21.11, $p<0.001)$. On the CogDis dimension, main effects of both IC status $(F=11.03)$ and age category $(F=10.47)$ were significant $(p=0.001)$, and not their interaction $(p>0.05)$. The ImpNon was influenced only by the IC status main effect $(F=23.82, p<0.001)$.

To further explore the relation between age categories and schizotypy dimensions, independent t-test analyses were interpreted. Adults (i.e., "over 18" category) scored significantly higher than adolescents (i.e., "under 18" category) in the UnEx and CogDis dimensions $(p<0.001)$, as well as in overall schizotypy $(p<0.05)$.

All in all, with the consideration of these post-hoc ANOVAs, it is worth mentioning the mean difference on overall sO-LIFE and the UnEx dimension by taking into account all three variables, namely the IC status, gender, and age category (Table 6). As it is evident in this table, scores of the CIC group in both age groups and genders are higher than the NIC group of this study. 
Table 6. Mean difference on overall SO-LIFE and the UnEx dimension in all participants according to their IC status, age category and gender: means followed by standard deviations.

\begin{tabular}{|c|c|c|c|c|c|}
\hline IC Status & Age Category & Gender & Overall sO-LIFE & UnEx & $\mathbf{N}$ \\
\hline \multirow[t]{9}{*}{ NIC } & \multirow[t]{3}{*}{ Under 18} & female & $18.03(6.99)$ & $5.82(2.82)$ & 34 \\
\hline & & male & $11.27(4.62)$ & $3.00(2.65)$ & 26 \\
\hline & & total & $15.10(6.91)$ & $4.60(3.07)$ & 60 \\
\hline & \multirow[t]{3}{*}{ Over 18} & female & $19.60(5.32)$ & $6.60(2.35)$ & 57 \\
\hline & & male & $17.22(6.58)$ & $5.84(2.35)$ & 50 \\
\hline & & total & $18.49(6.03)$ & $6.24(2.37)$ & 107 \\
\hline & \multirow[t]{3}{*}{ Total } & female & $19.01(6.01)$ & $6.31(2.55)$ & 91 \\
\hline & & male & $15.18(6.59)$ & $4.87(2.79)$ & 76 \\
\hline & & total & $17.27(6.55)$ & $5.65(2.75)$ & 167 \\
\hline \multirow[t]{9}{*}{ CIC } & \multirow[t]{3}{*}{ Under 18} & female & $21.26(6.14)$ & $6.67(2.65)$ & 27 \\
\hline & & male & $21.00(3.46)$ & $6.33(2.29)$ & 9 \\
\hline & & total & $21.19(5.55)$ & $6.58(2.53)$ & 36 \\
\hline & \multirow[t]{3}{*}{ Over 18} & female & $21.58(6.13)$ & $7.45(2.39)$ & 38 \\
\hline & & male & $21.79(5.61)$ & $7.50(2.50)$ & 14 \\
\hline & & total & $21.63(5.94)$ & $7.46(2.40)$ & 52 \\
\hline & \multirow[t]{3}{*}{ Total } & female & $21.45(6.09)$ & $7.12(2.51)$ & 65 \\
\hline & & male & $21.48(4.80)$ & $7.04(2.44)$ & 23 \\
\hline & & total & $21.45(5.76)$ & $7.10(2.48)$ & 88 \\
\hline \multirow[t]{9}{*}{ Total } & \multirow[t]{3}{*}{ Under 18} & female & $19.46(6.77)$ & $6.20(2.76)$ & 61 \\
\hline & & male & $13.77(6.09)$ & $3.86(2.93)$ & 35 \\
\hline & & total & $17.39(7.06)$ & $5.34(3.03)$ & 96 \\
\hline & \multirow[t]{3}{*}{ Over 18} & female & $20.39(5.71)$ & $6.94(2.39)$ & 95 \\
\hline & & male & $18.22(6.62)$ & $6.20(2.46)$ & 64 \\
\hline & & total & $19.52(6.16)$ & $6.64(2.44)$ & 159 \\
\hline & \multirow[t]{3}{*}{ Total } & female & $20.03(6.14)$ & $6.65(2.56)$ & 156 \\
\hline & & male & $16.65(6.75)$ & $5.37(2.86)$ & 99 \\
\hline & & total & $18.71(6.58)$ & $6.15(2.74)$ & 255 \\
\hline
\end{tabular}




\section{Discussion}

The experience of interacting with an imaginary friend is a profound one for most children. Although most of the childhood memories are prone to being forgotten with age, many adolescents and adults are still able to recall the memory of their special friend. These companions can serve several other functions in addition to being partners in play for children; from channeling their anger and being blamed for mistakes to functioning as a mediator in communication between the child and their parents (Taylor, 1999). The presence of ICs in the lives of children goes to the extent of taking up space and sitting at dinner table with others (Ames \& Learned, 1946). Furthermore, they are not always friendly and compliant or under the conscious control of the child (Taylor et al., 2007). Nevertheless, in most cases, children can tell that their ICs are 'make-believe' and not 'real' (Taylor \& Mottweiler, 2008).

Ever since the first published scientific works on ICs (Vostrovsky, 1895), personality traits of this group of children have been discussed. Moreover, there are studies that compared characteristics of adolescents and adults, grouped according to their childhood IC status (Gleason et al., 2003; Seiffge-Krenke, 1997). Theory of Mind (Davis, 2020; Giménez-Dasí et al., 2014; Taylor \& Carlson, 1997), creativity (Hoff, 2005; Kidd et al., 2010; Schaefer, 1969), and imaginative abilities including fantasy-proneness (Bouldin \& Pratt, 1999; Firth et al., 2015; Gleason et al., 2003; Seiffge-Krenke, 1997; Trionfi \& Reese, 2009) were reported to have associations with IC play. Additionally, hallucination-like experiences, reported in signal detection tasks, were found to occur more in participants with the CIC than the control group (Davis et al., 2019; Fernyhough et al., 2019; Pearson et al., 2001). One can consider these findings in light of the personality construct of schizotypy.

Schizotypy, as a multidimensional construct, manifests distinct profiles as a result of the interaction of its dimensions (Holt et al., 2008). Adopting a fully dimensional perspective to schizotypy, as in Claridge's model (Claridge \& Beech, 1995), results in considering both adaptive and potentially pathological sides to this multidimensional construct (Mohr \& Claridge, 2015). The concept of "happy schizotypes" (McCreery, 1997) arose from this view of schizotypy, plus considering the distinct profiles emerging from different interactions of its dimensions. It was observed, then, that "happy schizotypes" are the ones that score high on positive dimension (i.e., UnEx) and simultaneously low/average on negative (i.e., IntAn) and disorganization (i.e., CogDis) dimensions of schizotypy (Grant et al., 2018). 
Positive dimension of schizotypy measures perceptual abberations, magical ideation, and hallucinatory experiences (Mason et al., 2005). It was found to be associated with creativity (Batey \& Furnham, 2008; Mohr et al., 2001), anomalous experiences (Goulding, 2004; McCreery \& Claridge, 2002), and fantasy-proneness (Merckelbach et al., 2000; SánchezBernardos \& Avia, 2006).

As the main hypothesis, self-report of childhood ICs was associated with higher overall sO-LIFE, and the UnEx scores in adolescents and adults, with gender moderating the former but not the latter association. It was found that scores on the ImpNon dimension was also higher for the CIC group; a finding that was not predicted. Although preliminary independent groups t-test showed low significant difference between the two groups on the CogDis dimension, a post-hoc ANOVA revealed that this dimension was strongly influenced by the main effect of age category and probably also by other confounding variables not measured in this study. Lastly, there was no significant difference observed between the two groups on the IntAn dimension.

In general, these findings demonstrated that the history of CIC in adolescents and adults indicates a profile of schizotypy dimensions in line with the concept of "happy schizotype". In other words, this group of adolescents and adults scored higher than the ones without such experience on positive schizotypy (i.e., measured by the UnEx dimension), and did not differ much from the NIC group on negative (i.e., IntAn) and disorganization (i.e., CogDis) dimensions. The higher score of the CIC group on the ImpNon dimension can be discussed in light of the literature on creativity.

The association between having imaginary friends and being more creative was reported in several studies (Hoff, 2005; Kidd et al., 2010; Schaefer, 1969). Likewise, the ImpNon dimension of schizotypy, in addition to the UnEx dimension, was found to be associated with creativity (Batey \& Furnham, 2008; Perchtold-Stefan et al., 2021). This relation was also reported in a meta-analysis (Acar \& Sen, 2013). As such, it may be indirectly concluded that adolescents and adults with the CIC experience, as the more creative ones, score higher in the ImpNon dimension as well.

Another important finding was that those adolescents and adults of the NIC group who reported impersonation were not different from participants of the $\mathrm{CIC}$ group on overall sOLIFE and the UnEx dimension scores. These two groups were significantly different from the NIC group without impersonation. This finding can be explained by the phenomenological 
(Ames \& Learned, 1946) and personality (for example in the case of ToM and emotion understanding (Taylor et al., 2004) overlaps that exist between IC play and impersonation of imaginary characters. A crucial implication of this finding for future studies would be to bear in mind imaginary identities along with invisible ICs and personified objects in order to better understand this related phenomenon.

For a deeper understanding of personality and behavioral tendencies of different groups in this study, and also for the need of integrating the sO-LIFE schizotypy scale into personality and psychopathological classifications, two measures compatible with the HiTOP model (i.e., the ASEBA-YSR and the NEO-FFI) were investigated in relation to the sO-LIFE dimensions and the IC status of participants.

The correlation of two subscales of the ASEBA-YSR (i.e., Thought Problems and Withdrawn/Depressed), and positive (UnEx) and negative (IntAn) dimensions of sO-LIFE was examined in adolescents. The strong correlation of the Thought Problems subscale with the UnEx dimension and the moderate correlation of the Withdrawn/Depressed subscale with the IntAn dimension were expected because they tap onto roughly the same domains (Kotov et al., 2020).

The sharpest mean differences between the CIC and NIC groups of adolescents (with the CIC group scoring higher than the NIC group) were found on three subscales of the ASEBA-YSR; Thought Problems, Obsessive-Compulsive Problems, and PTSD Problems. The Thought Problems subscale captures symptoms (e.g., hearing voices and seeing things) similar to the items of the UnEx dimension and was introduced as a scale to measure positive schizotypy traits among children and adolescents (Kotov et al., 2020). As such, its observed difference between the two groups was in line with the findings of the main hypothesis. The Obsessive-Compulsive Problems subscale has four items in common with the Thought Problems subscale and they were found strongly correlated with each other among adolescents in this study $(r=0.78)$.

The difference found on the PTSD Problems subscale can be explained on two grounds. First, teens with CIC history were found to have hardship handling emotions and more stressed about social interactions (Bonne et al., 1999), probably due to their higher attentiveness and inclination toward social situations (Gleason et al., 2003). Therefore, as four items of this subscale pertain to nervousness and tension, this might explain their higher experienced psychological distress compared to their peers. Second, one reason underlying the creation of 
ICs among children is in response to trauma (Taylor, 1999). This link has been discussed in the literature on dissociation as well (McLewin \& Muller, 2006), albeit not necessarily meaning that having CICs predisposes adolescents to pathological dissociation (Taylor et al., 2010).

Although pathological tendencies were examined between the two groups of adolescents by comparing the scores of the ASEBA-YSR syndromes, we cannot put emphasis on the findings as a wellbeing measure has not been employed in this study. Therefore, it seems crucial for the future studies of the kind to also include such measure for the purpose of reliably comparing participants with and without CIC experience according to their pathological tendencies.

The correlations of the NEO-FFI domains with sO-LIFE dimensions were examined among adults in this study. The neuroticism domain was positively related to overall sO-LIFE and the CogDis dimension scores; findings in line with previous studies (Asai et al., 2011). This domain of the Five Factor Model (FFM) reflects vulnerability to distress (Widiger \& Costa $\mathrm{Jr}$, 2002), and as such, expected to be strongly correlated with the CogDis dimension that measures low concentration and decision-making abilities. The extraversion domain and the IntAn dimension are in many ways contrary to each other, therefore their negative relationship was found to be strong and significant. Studies demonstrated that openness to experience and positive schizotypy are strongly related (Asai et al., 2011; Ross et al., 2002); a finding that was not replicated in this study. The agreeableness and conscientiousness domains, same as extraversion, demonstrated a negative trend of correlations with SO-LIFE dimensions among adults in this study.

The only domain of NEO-FFI that differed between the NIC and CIC group was neuroticism. The CIC group scored significantly higher than the NIC group in this domain. This finding is in line with the aforementioned discussion (Bonne et al., 1999) on higher emotionality of this group of participants. Higher reactivity to negative emotional stressors can be one of the reasons that trigger playing with an IC in childhood.

The findings of this study can be interpreted in several ways: Firstly, having imaginary friends in childhood could be associated with a set of personality characteristics in adolescents and adults. Capturing this set of characteristics, at least partially, in schizotypy dimensions helps us understand and explain this phenomenon more systematically. Secondly, considering schizotypy as a multi- and fully dimensional organization have implications for both health and psychopathology. In this regard, distinct profiles emerge from the interaction of this construct's 
dimensions. Thirdly, integrating schizotypy into higher order classifications of mental phenomena that are aligned with the dimensional nature of this personality construct seems to improve its utility in both research and practice.

The design of this study did not benefit from random sampling which is a notable limitation for generalizability of the findings to the population. Representative sample of the adolescent and adult populations will be needed to be assessed to validate these results. Additionally, longitudinal research following children with IC through their adolescence and adulthood is needed to determine the schizotypy levels for a better understanding of its developmental pathway. Furthermore, in this study, reports of CIC in adolescents and adults relied solely on their retrospective accounts of this experience, which was shown to underestimate its true prevalence (McAnally et al., 2021).

By considering the relation of having imaginary friends in childhood and demonstrating a profile of "happy schizotypy", future research can shed light on this association by investigating specific traits and states related to this profile according to the IC status. Furthermore, the phenomenological accounts of IC experience with the consideration of its different types (e.g., PO and invisible IC) might better capture the diversity and functions of this fanatsy play in the lives of children.

\section{Authors' Note}

Data and study materials are available and can be obtained by contacting corresponding author. This study was not preregistered.

\section{Authors' Contribution}

TZ designed the study, organized the data collection, and drafted the first version of the manuscript. AP contributed to the statistical analyses and was actively involved in revising the manuscript. MP was actively involved in revising the manuscript.

\section{Declaration of Interests}

The Authors declare that there is no conflict of interest. 


\section{References}

Acar, S., \& Sen, S. (2013). A multilevel meta-analysis of the relationship between creativity and schizotypy. Psychology of Aesthetics, Creativity, and the Arts, 7(3), 214-228. https://doi.org/10.1037/a0031975

Achenbach, T. M., \& Rescorla, L. A. (2001). Manual for the ASEBA school-age forms \& profiles: An integrated system of multi-informant assessment. University of Vermont, Research Center for Children, Youth, \& Families.

Acredolo, L., Goodwyn, S., \& Fulmer, A. (1995, April). Why some children create imaginary companions: Clues from infant and toddler play preferences [Poster presentation]. Biennial Meetings of the Society for Research in Child Development, Indianapolis, IN.

Ames, L. B., \& Learned, J. (1946). Imaginary companions and related phenomena. Pedagogical Seminary and Journal of Genetic Psychology, 69(2), 147-167. https://doi.org/10.1080/08856559.1946.10533385

Asai, T., Sugimori, E., Bando, N., \& Tanno, Y. (2011). The hierarchic structure in schizotypy and the five-factor model of personality. Psychiatry Research, 185(1), 78-83. https://doi.org/10.1016/j.psychres.2009.07.018

Batey, M., \& Furnham, A. (2008). The relationship between measures of creativity and schizotypy. Personality and Individual Differences, 45(8), 816-821.

Bender, L., \& Vogel, B. F. (1941). Imaginary companions of children. American Journal of Orthopsychiatry, 11(1), 56-65. https://doi.org/10.1111/j.1939-0025.1941.tb05778.x

Bentall, R. P. (2014). Hallucinatory experiences. In E. Cardeña, S. J. Lynn, \& S. Krippner (Eds.), Varieties of anomalous experience: Examining the scientific evidence (2nd ed., pp. 109-143). American Psychological Association. https://doi.org/10.1037/14258005

Bentall, R. P., Claridge, G. S., \& Slade, P. D. (1989). The multidimensional nature of schizotypal traits: A factor analytic study with normal subjects. British Journal of Clinical Psychology, 28(4), 363-375. https://doi.org/10.1111/j.20448260.1989.tb00840.x

Bentall, R. P., \& Slade, P. D. (1985). Reality testing and auditory hallucinations: A signal detection analysis. British Journal of Clinical Psychology, 24 (3), 159-169. https://doi.org/10.1111/j.2044-8260.1985.tb01331.x 
Bleuler, E. (1950). Dementia praecox or the group of schizophrenias. (J. Zinkin, Trans.). International Universities Press. (Original work published in 1911).

Bonne, O., Canetti, L., Bachar, E., De-Nour, A. K., \& Shalev, A. (1999). Childhood imaginary companionship and mental health in adolescence. Child Psychiatry and Human Development, 29(4), 277-286. https://doi.org/10.1023/a:1021345015520

Bouldin, P., \& Pratt, C. (1999). Characteristics of preschool and school-age children with imaginary companions. Journal of Genetic Psychology: Research and Theory on Human Development, 160(4), 397-410. https://doi.org/10.1080/00221329909595553

Cardeña, E., Lynn, S. J., \& Krippner, S. (2014). Introduction: Anomalous experiences in perspective. In E. Cardeña, S. J. Lynn, \& S. Krippner (Eds.), Varieties of anomalous experience: Examining the scientific evidence (2nd ed., pp. 3-20). American Psychological Association. https://doi.org/10.1037/14258-001

Chapman, L. J., Chapman, J. P., Kwapil, T. R., Eckblad, M., \& Zinser, M. C. (1994). Putatively psychosis-prone subjects 10 years later. Journal of Abnormal Psychology, 103(2), 171-183. https://doi.org/10.1037//0021-843x.103.2.171

Chapman, L. J., Chapman, J. P., Numbers, J. S., Edell, W. S., Carpenter, B. N., \& Beckfield, D. (1984). Impulsive nonconformity as a trait contributing to the prediction of psychotic-like and schizotypal symptoms. Journal of Nervous and Mental Disease. https://doi.org/10.1097/00005053-198411000-00007

Cicero, D. C., Martin, E. A., Becker, T. M., Docherty, A. R., \& Kerns, J. G. (2014). Correspondence between psychometric and clinical high risk for psychosis in an undergraduate population. Psychological Assessment, 26(3), 901-915. https://doi.org/10.1037/a0036432

Claridge, G. (1997). Theoritical background issues. In G. Claridge (Ed.), Schizotypy: Implications for illness and health (pp. 3-18). Oxford University Press.

Claridge, G., \& Beech, T. (1995). Fully and quasi-dimensional constructions of schizotypy. In A. Raine, T. Lencz, \& S. Mednick (Eds.), Schizotypal personality. (pp. 192-216). Cambridge University Press. https://doi.org/10.1017/CBO9780511759031.010

Cohen, A. S., \& Davis, T. E. (2009). Quality of life across the schizotypy spectrum: Findings from a large nonclinical adult sample. Comprehensive Psychiatry, 50(5), 408-414. https://doi.org/10.1016/j.comppsych.2008.11.002

Conway, C. C., Forbes, M. K., Forbush, K. T., Fried, E. I., Hallquist, M. N., Kotov, R., Mullins-Sweatt, S. N., Shackman, A. J., Skodol, A. E., South, S. C., Sunderland, M., Waszczuk, M. A., Zald, D. H., Afzali, M. H., Bornovalova, M. A., Carragher, N., 
Docherty, A. R., Jonas, K. G., Krueger, R., F., ... Eaton, N. R. (2019). A Hierarchical Taxonomy Of Psychopathology can transform mental health research. Perspectives on Psychological Science, 14(3), 419-436. https://doi.org/10.1177/1745691618810696

Costa, P. T., \& McCrae, R. R. (1992). Professional manual: Revised NEO Personality Inventory (NEO-PI-R) and NEO Five-Factor Inventory (NEO-FFI). Psychological Assessment Resources.

Davis, P. E. (2020). Imaginary friends: How imaginary minds mimic real life. In A. Abraham (Ed.), The Cambridge handbook of the imagination (pp. 373-389). Cambridge University Press. https://doi.org/10.1017/9781108580298.023

Davis, P. E., Webster, L. A. D., Fernyhough, C., Ralston, K., Kola-Palmer, S., \& Stain, H. J. (2019). Adult report of childhood imaginary companions and adversity relates to concurrent prodromal psychosis symptoms. Psychiatry Research, 271, 150-152. https://doi.org/10.1016/j.psychres.2018.11.046

Edmundson, M., Lynam, D. R., Miller, J. D., Gore, W. L., \& Widiger, T. A. (2011). A fivefactor measure of schizotypal personality traits. Assessment, 18(3), 321-334. https://doi.org/10.1177/1073191111408228

Fernyhough, C., Bland, K., Meins, E., \& Coltheart, M. (2007). Imaginary companions and young children's responses to ambiguous auditory stimuli: Implications for typical and atypical development. Journal of Child Psychology and Psychiatry, 48(11), 10941101. https://doi.org/10.1111/j.1469-7610.2007.01789.x

Fernyhough, C., Watson, A., Bernini, M., Moseley, P., \& Alderson-Day, B. (2019). Imaginary companions, inner speech, and auditory verbal hallucinations: What are the relations? Frontiers in Psychology, 10, 1665. https://doi.org/10.3389/fpsyg.2019.01665

Firth, L., Alderson-Day, B., Woods, N., \& Fernyhough, C. (2015). Imaginary companions in childhood: Relations to imagination skills and autobiographical memory in adults. Creativity Research Journal, 27(4), 308-313. https://doi.org/10.1080/10400419.2015.1087240

Fonseca-Pedrero, E., Chan, R. C. K., Debbané, M., Cicero, D., Zhang, L. C., Brenner, C., Barkus, E., Linscott, R. J., Kwapil, T., Barrantes-Vidal, N., Cohen, A., Raine, A., Compton, M. T., Tone, E. B., Suhr, J., Muñiz, J., de Albéniz, A. P., Fumero, A., Giakoumaki, S., ... Ortuño-Sierra, J. (2018). Comparisons of schizotypal traits across 12 countries: Results from the International Consortium for Schizotypy Research. Schizophrenia Research, 199, 128-134. https://doi.org/10.1016/j.schres.2018.03.021 
Fonseca-Pedrero, E., Debbané, M., Rodríguez-Testal, J. F., Cohen, A. S., Docherty, A. R., \& Ortuño-Sierra, J. (2021). Schizotypy: The way ahead. Psicothema, 33(1), 16-27. https://doi.org/10.7334/psicothema2019.285

Fonseca-Pedrero, E., Lemos-Giráldez, S., Paino, M., Sierra-Baigrie, S., \& Muñiz, J. (2012). Phenotypic expression of schizotypal traits in an adolescent population. Journal of Personality Disorders, 26(4), 539-550. https://doi.org/10.1521/pedi.2012.26.4.539

Gianotti, L. R. R., Mohr, C., Pizzagalli, D., Lehmann, D., \& Brugger, P. (2001). Associative processing and paranormal belief. Psychiatry and Clinical Neurosciences, 55(6), 595603. https://doi.org/https://doi.org/10.1046/j.1440-1819.2001.00911.x

Giménez-Dasí, M., Pons, F., \& Bender, P. (2014). Imaginary companions, theory of mind and emotion understanding in young children. European Early Childhood Education Research Journal, 24. https://doi.org/10.1080/1350293X.2014.919778

Gleason, T. R. (2002). Social provisions of real and imaginary relationships in early childhood. Developmental Psychology, 38(6), 979. https://doi.org/10.1037/00121649.38.6.979

Gleason, T. R., Jarudi, R. N., \& Cheek, J. M. (2003). Imagination, personality, and imaginary companions. Social Behavior and Personality: An International Journal, 31(7), 721737. https://doi.org/10.2224/sbp.2003.31.7.721

Gooding, D. C., Tallent, K. A., \& Matts, C. W. (2005). Clinical status of at-risk individuals 5 years later: Further validation of the psychometric high-risk strategy. Journal of Abnormal Psychology, 114(1), 170. https://doi.org/10.1037/0021-843X.114.1.170

Goulding, A. (2004). Schizotypy models in relation to subjective health and paranormal beliefs and experiences. Personality and Individual Differences, 37(1), 157-167. https://doi.org/10.1016/j.paid.2003.08.008

Grant, P., Green, M. J., \& Mason, O. J. (2018). Models of schizotypy: The importance of conceptual clarity. Schizophrenia Bulletin, 44(suppl_2), S556-S563. https://doi.org/10.1093/schbul/sby012

Gurrera, R. J., Dickey, C. C., Niznikiewicz, M. A., Voglmaier, M. M., Shenton, M. E., \& McCarley, R. W. (2005). The Five-Factor Model in schizotypal personality disorder. Schizophrenia Research, 80(2-3), 243-251. https://doi.org/10.1016/j.schres.2005.08.002

Hoff, E. V. (2005). Imaginary companions, creativity, and self-image in middle childhood. Creativity Research Journal, 17(2-3), 167-180. https://doi.org/10.1080/10400419.2005.9651477 
Holt, N., Simmonds-Moore, C., \& Moore, S. (2008). Benign schizotypy: Investigating differences between clusters of schizotype on paranormal belief, creativity, intelligence and mental health. In S. Sherwood (Ed.), Proceedings of Presented Papers: The Parapsychological Association 51st Annual Convention (pp. 82-96). Parapsychological Association.

Horan, W. P., Brown, S. A., \& Blanchard, J. J. (2007). Social anhedonia and schizotypy: The contribution of individual differences in affective traits, stress, and coping. Psychiatry Research, 149(1), 147-156. https://doi.org/https://doi.org/10.1016/j.psychres.2006.06.002

Jones, S. R., Fernyhough, C., de-Wit, L., \& Meins, E. (2008). A message in the medium? Assessing the reliability of psychopathology e-questionnaires. Personality and Individual Differences, 44(2), 349-359. https://doi.org/https://doi.org/10.1016/j.paid.2007.08.014

Jones, T., Caulfield, L., Wilkinson, D., \& Weller, L. (2011). The relationship between nonclinical schizotypy and handedness on divergent and convergent creative problemsolving tasks. Creativity Research Journal, 23(3), 222-228. https://doi.org/10.1080/10400419.2011.595964

Kerns, J. G. (2006). Schizotypy facets, cognitive control, and emotion. Journal of Abnormal Psychology, 115(3), 418-427. https://doi.org/10.1037/0021-843x.115.3.418

Kidd, E., Rogers, P., \& Rogers, C. (2010). The personality correlates of adults who had imaginary companions in childhood. Psychological Reports, 107(1), 163-172. https://doi.org/10.2466/02.04.10.pr0.107.4.163-172

Kotov, R., Jonas, K. G., Carpenter, W. T., Dretsch, M. N., Eaton, N. R., Forbes, M. K., Forbush, K. T., Hobbs, K., Reininghaus, U., Slade, T., South, S. C., Sunderland, M., Waszczuk, M. A., Widiger, T. A., Wright, A. G. C., Zald, D. H., Krueger, R. F., \& Watson, D. (2020). Validity and utility of Hierarchical Taxonomy Of Psychopathology (HiTOP): I. Psychosis superspectrum. World Psychiatry: Official Journal of the World Psychiatric Association (WPA), 19(2), 151-172. https://doi.org/10.1002/wps.20730

Kotov, R., Krueger, R. F., Watson, D., Achenbach, T. M., Althoff, R. R., Bagby, R. M., Brown, T. A., Carpenter, W. T., Caspi, A., Clark, L. A., Eaton, N. R., Forbes, M. K., Forbush, K. T., Goldberg, D., Hasin, D., Hyman, S. E., Ivanova, M. Y., Lynam, D. R., Markon, K., ...Zimmerman, M. (2017). The Hierarchical Taxonomy Of Psychopathology (HiTOP): A dimensional alternative to traditional nosologies. 
Journal of Abnormal Psychology, 126(4), 454-477.

https://doi.org/10.1037/abn0000258

Kraepelin, E. (1919). Dementia praecox and paraphrenia. Edinburgh, Scotland: Livingstone. (Original work published 1913).

Kwapil, T. R., \& Barrantes-Vidal, N. (2015). Schizotypy: Looking back and moving forward. Schizophrenia Bulletin, 41 Suppl 2(Suppl 2), S366-373. https://doi.org/10.1093/schbul/sbu186

Kwapil, T. R., \& Chun, C. A. (2015). The psychometric assessment of schizotypy. In O. Mason, \& G. Claridge (Eds.), Schizotypy: New dimensions (pp. 7-32). Routledge. Lenzenweger, M. F. (1998). Schizotypy and schizotypic psychopathology: Mapping an alternative expression of schizophrenia liability. In M. F. Lenzenweger \& R. H. Dworkin (Eds.), Origins and development of schizophrenia: Advances in experimental psychopathology. (pp. 93-121). American Psychological Association. https://doi.org/10.1037/10305-004

Lin, Q., Fu, H., Wan, Y., Zhou, N., \& Xu, H. (2018). Chinese children's imaginary companions: Relations with peer relationships and social competence. International Journal of Psychology, 53(5), 388-396. https://doi.org/10.1002/ijop.12392

Lynn, S. J., \& Rhue, J. W. (1988). Fantasy proneness: Hypnosis, developmental antecedents, and psychopathology. American Psychologist, 43(1), 35-44. https://doi.org/10.1037/0003-066X.43.1.35

Mason, O., Claridge, G., \& Jackson, M. (1995). New scales for the assessment of schizotypy. Personality and Individual Differences, 18(1), 7-13. https://doi.org/10.1016/01918869(94)00132-C

Mason, O., Linney, Y., \& Claridge, G. (2005). Short scales for measuring schizotypy. Schizophrenia Research, 78(2-3), 293-296. https://doi.org/10.1016/j.schres.2005.06.020

Mauro, J. (1991). The friend that only I can see: A longitudinal investigation of children's imaginary companions [Unpublished doctoral dissertation]. University of Oregon.

McAnally, H. M., Forsyth, B. J., Taylor, M., \& Reese, E. (2021). Imaginary companions in childhood: What can prospective longitudinal research tell us about their fate by adolescence? The Journal of Creative Behavior, 55(1), 276-283.

McCreery, C. (1997). Hallucinations and arousability: Pointers to a theory of psychosis. In G. Claridge (Ed.), Schizotypy: Implications for illness and health (pp. 251-273). Oxford University Press. 
McCreery, C., \& Claridge, G. (2002). Healthy schizotypy: The case of out-of-the-body experiences. Personality and Individual Differences, 32(1), 141-154. https://doi.org/10.1016/S0191-8869(01)00013-7

McLewin, L. A., \& Muller, R. T. (2006). Childhood trauma, imaginary companions, and the development of pathological dissociation. Aggression and Violent Behavior, 11(5), 531-545. https://doi.org/10.1016/j.avb.2006.02.001

Meehl, P. E. (1962). Schizotaxia, schizotypy, schizophrenia. American Psychologist, 17(12), 827-838. https://doi.org/10.1037/h0041029

Merckelbach, H., Muris, P., Horselenberg, R., \& Stougie, S. (2000). Dissociative experiences, response bias, and fantasy proneness in college students. Personality and Individual Differences, 28, 49-58. https://doi.org/10.1016/S0191-8869(99)00079-3

Merckelbach, H., Otgaar, H., \& Lynn, S. J. (2021). Empirical research on fantasy proneness and its correlates 2000-2018: A meta-analysis. Psychology of Consciousness: Theory, Research, and Practice. https://doi.org/10.1037/cns0000272

Miller, P., Byrne, M., Hodges, A., Lawrie, S. M., Owens, D. G. C., \& Johnstone, E. C. (2002). Schizotypal components in people at high risk of developing schizophrenia: Early findings from the Edinburgh High-Risk Study. British Journal of Psychiatry, 179-184.

Mohr, C., \& Claridge, G. (2015). Schizotypy--do not worry, it is not all worrisome. Schizophrenia Bulletin, 41 Suppl 2(Suppl 2), S436-443. https://doi.org/10.1093/schbul/sbu185

Mohr, C., Graves, R. E., Gianotti, L. R., Pizzagalli, D., \& Brugger, P. (2001). Loose but normal: A semantic association study. Journal of Psycholinguistic Research, 30(5), 475-483. https://doi.org/10.1023/a:1010461429079

Moorman, E. L., \& Samuel, D. B. (2018). Representing schizotypal thinking with dimensional traits: A case for the Five Factor Schizotypal Inventory. Psychological Assessment, 30(1), 19-30. https://doi.org/10.1037/pas0000497

Morrison, A. P., Bentall, R. P., French, P., Kilcommons, A., Knight, A., Kreutz, M., \& Lewis, S. W. (2002). Randomised controlled trial of early detection and cognitive therapy for preventing transition to psychosis in high risk individuals: Study design and interim analysis of transition rate and psychological risk factors. British Journal of Psychiatry, 78-84.

Pearson, D. (1998). The social acceptability of children hearing voices. University of Leicester. 
Pearson, D., Burrow, A., FitzGerald, C., Green, K., Lee, G., \& Wise, N. (2001). Auditory hallucinations in normal child populations. Personality and Individual Differences, 401-407.

Perchtold-Stefan, C. M., Rominger, C., Papousek, I., \& Fink, A. (2021). Antisocial schizotypy is linked to malevolent creativity. Creativity Research Journal, 1-13. https://doi.org/10.1080/10400419.2021.2012633

Posey, T. B., \& Losch, M. E. (1983). Auditory hallucinations of hearing voices in 375 normal subjects. Imagination, Cognition and Personality, 3(2), 99-113. https://doi.org/10.2190/74V5-HNXN-JEY5-DG7W

Raine, A. (1991). The SPQ: A scale for the assessment of schizotypal personality based on DSM-III-R criteria. Schizophrenia Bulletin, 17(4), 555-564. https://doi.org/10.1093/schbul/17.4.555

Rawlings, D., \& Freeman, J. L. (1997). Measuring paranoia/suspiciousness. In G. Claridge (Ed.), Schizotypy: Implications for illness and health. (pp. 38-60). Oxford University Press. https://doi.org/10.1093/med:psych/9780198523536.003.0003

Rock, A. J., Abbott, G., Childargushi, H., \& Kiehne, M. (2008). The effect of shamanic-like stimulus conditions and the cognitive-perceptual factor of schizotypy on phenomenology. North American Journal of Psychology, 10, 79-98.

Rosellini, A. J., \& Brown, T. A. (2011). The NEO Five-Factor Inventory: Latent structure and relationships with dimensions of anxiety and depressive disorders in a large clinical sample. Assessment, 18(1), 27-38. https://doi.org/10.1177/1073191110382848

Ross, S. R., Lutz, C. J., \& Bailley, S. E. (2002). Positive and negative symptoms of schizotypy and the Five-Factor Model: A domain and facet level analysis. Journal of Personality Assessment, 79(1), 53-72. https://doi.org/10.1207/s15327752jpa7901_04

Sánchez-Bernardos, M. L., \& Avia, M. D. (2006). The relationship between fantasy proneness and schizotypy in adolescents. The Journal of Nervous and Mental Disease, 194(6), 411-414.

Schaefer, C. E. (1969). Imaginary companions and creative adolescents. Developmental Psychology, 1(6, Pt.1), 747-749. https://doi.org/10.1037/h0028270

Schofield, K., \& Claridge, G. (2007). Paranormal experiences and mental health: Schizotypy as an underlying factor. Personality and Individual Differences, 43(7), 1908-1916. https://doi.org/10.1016/j.paid.2007.06.014 
Seiffge-Krenke, I. (1997). Imaginary companions in adolescence: Sign of a deficient or positive development. Journal of Adolescence, 20(2), 137-154. https://doi.org/10.1006/jado.1996.0072

Shi, J., Yao, Y., Zhan, C., Mao, Z., Yin, F., \& Zhao, X. (2018). The relationship between Big Five personality traits and psychotic experience in a large non-clinical youth sample: The mediating role of emotion regulation. Frontiers in Psychiatry, 9. https://doi.org/10.3389/fpsyt.2018.00648

Svendsen, M. (1934). Children's imaginary companions. Archives of Neurology \& Psychiatry, 32, 985-999. https://doi.org/10.1001/archneurpsyc.1934.02250110073006

Tabak, N. T., \& Weisman de Mamani, A. G. (2013). Latent profile analysis of healthy schizotypy within the extended psychosis phenotype. Psychiatry Research, 210(3), 1008-1013. https://doi.org/10.1016/j.psychres.2013.08.006

Taylor, M. (1999). Imaginary companions and the children who create them. Oxford University Press.

Taylor, M., \& Carlson, S. M. (1997). The relation between individual differences in fantasy and theory of mind. Child Development, 68(3), 436-455.

Taylor, M., Carlson, S. M., Maring, B. L., Gerow, L., \& Charley, C. M. (2004). The characteristics and correlates of fantasy in school-age children: Imaginary companions, impersonation, and social understanding. Developmental Psychology, 40(6), 1173-1187. https://doi.org/10.1037/0012-1649.40.6.1173

Taylor, M., Carlson, S. M., \& Shawber, A. B. (2007). Autonomy and control in children's interactions with imaginary companions. Proceedings of the British Academy (Vol. 147, pp. 81-100). Oxford University Press.

Taylor, M., Hodges, S. D., \& Kohányi, A. (2003). The illusion of independent agency: Do adult fiction writers experience their characters as having minds of their own? Imagination, Cognition and Personality, 22(4), 361-380. https://doi.org/10.2190/FTG3-Q9T0-7U26-5Q5X

Taylor, M., Hulette, A. C., \& Dishion, T. J. (2010). Longitudinal outcomes of young highrisk adolescents with imaginary companions. Developmental Psychology, 46(6), 1632-1636. https://doi.org/10.1037/a0019815

Taylor, M., \& Mottweiler, C. M. (2008). Imaginary companions: Pretending they are real but knowing they are not. American Journal of Play, 1(1), 47-54.

Taylor, M., Sachet, A. B., Maring, B. L., \& Mannering, A. M. (2013). The assessment of elaborated role-play in young children: Invisible friends, personified objects, and 
Childhood imaginary companion and schizotypy in adolescents and adults

pretend identities. Social Development, 22(1), 75-93.

https://doi.org/10.1111/sode.12011

Trionfi, G., \& Reese, E. (2009). A good story: Children with imaginary companions create richer narratives. Child Development, 80(4), 1301-1313. https://doi.org/10.1111/j.1467-8624.2009.01333.x

van Os, J., Hanssen, M., Bijl, R. V., \& Ravelli, A. (2000). Strauss (1969) revisited: A psychosis continuum in the general population? Schizophrenia Research, 45(1), 1120. https://doi.org/10.1016/S0920-9964(99)00224-8

Vostrovsky, C. (1895). A Study of Imaginary Companions. Education, 393-398.

Widiger, T. A., \& Costa Jr, P. T. (2002). Five-Factor Model personality disorder research. In In P. T. Costa, Jr. \& T. A. Widiger (Eds.), Personality Disorders and the Five-Factor Model of Personality (2nd ed., pp. 59-87). American Psychological Association. https://doi.org/10.1037/10423-005

Widiger, T. A., \& Costa Jr, P. T. (Eds.). (2013). Personality disorders and the Five-Factor Model of personality (3rd ed.). American Psychological Association. https://doi.org/10.1037/13939-000 


\section{Appendix 1 (English Translation of Imaginary Companion Questionnaire)}

\section{Initial Description:}

Imaginary friends are pretend characters or creatures that you might have played with, talked with, and referred to by a specific name for a long time (at least several months). Importantly, they were seen by you to be endowed with human-like attributes and you treated them as your friend or playmate. Imaginary friends could be invisible (unobservable by others), or toys/dolls that had an air of reality for you and you played and talked with.

Imaginary identities are impersonated characters that you regularly (part of everyday, for at least several months) acted out yourself in a way that you talked like that character and liked to be called by that character's name and be treated accordingly (this excludes those kinds of role-playing games with other children, in which you played the role of a doctor or a firefighter, for example).

\section{Main Questions:}

1) Based on these descriptions, have you ever had imaginary friends while growing up? Options: yes/no

If yes:

2) What type was your imaginary friend? Options: Invisible/Toy (personified object)

If no: Have you ever had imaginary identities? Options: yes/no

\section{Complementary Questions:}

1) What was his/her name?

2) What did he/she look like?

3) What characteristics did he/she have?

4) Did he/she have a gender? What was it?

5) How often did you play with her/him?

6) Can you recall a situation of play or conversation with her/him? Describe it. 